\title{
Ubiquitin-dependent degradation of the yeast Mat $\alpha 2$ repressor enables a switch in developmental state
}

\author{
Jeffrey D. Laney ${ }^{1,2}$ and Mark Hochstrasser ${ }^{1,3}$ \\ ${ }^{1}$ Department of Molecular Biophysics and Biochemistry, Yale University, New Haven, Connecticut 06520-8114, USA; \\ ${ }^{2}$ Department of Molecular Biology, Cell Biology, and Biochemistry, Brown University, Providence, Rhode Island 02912, USA
}

\begin{abstract}
Developmental transitions in eukaryotic cell lineages revolve around two general processes: the dismantling of the regulatory program specifying an initial differentiated state and its replacement by a new system of regulators. However, relatively little is known about the mechanisms by which a previous regulatory state is inactivated. Protein degradation is implicated in a few examples, but the molecular reasons that a formerly used regulator must be removed are not understood. Many yeast strains undergo a developmental transition in which cells of one mating type differentiate into a distinct cell type by a programmed genetic rearrangement at the MAT locus. We find that Mat 2 , a MAT-encoded transcriptional repressor that is key to creating several cell types, must be rapidly degraded for cells to switch their mating phenotype properly. Strikingly, ubiquitin-dependent proteolysis of $\alpha 2$ is required for two mechanistically distinct purposes: It allows the timely inactivation of one transcriptional repressor complex, and it prevents the de novo assembly of a different, inappropriate regulatory complex. Analogous epigenetic mechanisms for reprogramming transcription are likely to operate in many developmental pathways.
\end{abstract}

[Keywords: Saccharomyces cerevisiae; differentiation; protein degradation; mating-type switching]

Received May 23, 2003; revised version accepted July 10, 2003.

During the development of eukaryotic organisms, the establishment of specific cell lineages from a multipotent progenitor often involves multiple differentiation steps that are regulated, at least in part, at the level of gene transcription. For example, at each stage in the differentiation of mammalian lymphocytes, myoblasts, osteoblasts, chondrocytes, and adipocytes, combinations of transcription factors distinct from those used in the previous developmental stage successively control cell-type specification (Black and Olson 1998; Glimcher and Singh 1999; Rosen and Spiegelman 2000; Akiyama et al. 2002; Nakashima et al. 2002). Therefore, as cells progress along a developmental pathway, they switch from one state of differentiation to another by changing gene expression programs. Although it is clear that the regulatory factors important for determining a new developmental stage are activated in response to specific inducing signals, the inactivation of the master regulators that had defined the eclipsed developmental state has remained largely unexplored.

Because of its irreversibility and speed, selective protein degradation is a common regulatory strategy used by

${ }^{3}$ Corresponding author.

E-MAIL mark.hochstrasser@yale.edu; FAX (203) 432-5175.

Article published online ahead of print. Article and publication date are at http://www.genesdev.org/cgi/doi/10.1101/gad.1115703. cells, and one well-suited to dismantling an existing regulatory network during cell state transitions. Diverse processes that involve changes in cellular state, such as cell cycle progression, signal transduction, and apoptosis, all depend on substrate-specific proteolytic mechanisms (Hochstrasser 1995; Hershko and Ciechanover 1998). Several different developmental pathways also appear to use selective protein degradation (Hoyt et al. 1982; Herskowitz 1985; Edgar et al. 1986; Kellerman et al. 1990; Lange and Hengge-Aronis 1994; Li et al. 1997; Tang et al. 1997; Pan et al. 2001). However, in eukaryotes, a mechanistic explanation for why a particular developmental regulator must be degraded has not previously been elucidated. Such regulatory proteolysis in eukaryotic organisms usually involves the ubiquitin (Ub)-proteasome system. In this highly conserved system, protein substrates are marked for destruction by the covalent attachment of a polyUb chain(s), which targets them to a large protease called the $26 \mathrm{~S}$ proteasome. The assembly of these $\mathrm{Ub}$ chains is catalyzed by a series of enzymes, two of which, the E2 Ub-conjugating enzyme (Ubc) and the E3 Ub-protein ligase, are largely responsible for substrate-specific recognition and ubiquitination (Hershko and Ciechanover 1998).

Here we investigate whether a cell's ability to rid itself of a specific transcription factor by Ub-mediated proteolysis is essential for the differentiation of the yeast Sac- 
charomyces cerevisiae. This unicellular eukaryote has three distinct cell types: two haploid variants $(\mathbf{a}$ and $\alpha)$ that can mate with each other to form the third type, a nonmating a/ $\alpha$ diploid. These different cellular phenotypes are determined by the genetic information present at the mating-type (MAT) locus, which encodes a group of transcriptional regulators that control mating and differentiation (Herskowitz 1985; Nasmyth and Shore 1987). In most strains found in the wild (homothallic strains), the mating phenotype is unstable, and cells of one haploid mating type differentiate into the opposite cell type (Oshima and Takano 1971; Hicks and Herskowitz 1976). This is accomplished by a highly regulated gene conversion process in which the genetic information at the MAT locus is replaced with DNA sequences for the other mating-type allele; these sequences are copied from one of two distantly located and transcriptionally silent chromosomal loci (Haber 1998). The phenotypic changes associated with such a genetic exchange occur within the span of a single division cycle. Hence, the gene expression programs responsible for determining mating phenotype must be rapidly dismantled following genetic switching at the MAT locus. These observations suggest that the Mat transcription factors that ultimately control cell type are short-lived proteins (Nasmyth and Shore 1987). If these regulatory factors were stable, their persistence after a MAT genetic switch could derail the cell-type-specific gene expression programs necessary for proper differentiation into the new haploid cell state.

Indeed, direct measurements of protein turnover have revealed that each of the Mat transcription factors is rapidly degraded in vivo (Hochstrasser and Varshavsky 1990; Johnson 1997; Johnson et al. 1998). The Ub-proteasome system is responsible for the destruction of these proteins (Hochstrasser et al. 1991; Chen et al. 1993; Chen and Hochstrasser 1995; Johnson 1997; Johnson et al. 1998). For example, the repressor protein Mat $\alpha 2(\alpha 2)$ has an in vivo half-life of $\sim 5 \mathrm{~min}$ and is targeted for proteasomal degradation by at least two Ub-dependent pathways involving four different E2s/Ubcs. Ubc4 and Ubc5 define one $\alpha 2$ proteolysis pathway, whereas the other requires Ubc6 and Ubc7, as well as a RING-domain E3 called Doa10 (Chen et al. 1993; Swanson et al. 2001). This latter ubiquitination pathway recognizes a well-defined degradation signal within the $\mathrm{N}$ terminus of $\alpha 2$, whose key determinant is the exposed hydrophobic face of an amphipathic helix (Johnson et al. 1998). Notwithstanding this relatively well-characterized mechanism for $\alpha 2$ proteolysis, the physiological relevance of its rapid degradation has not been determined.

Although it is reasonable to hypothesize that the degradation of $\alpha 2$ after a MAT genetic switch is necessary for proper cell-type regulation, this need not be the case. Other, nonproteolytic inactivation mechanisms could supersede any variations in degradation rate. For example, the degradation rate of the critical metabolic enzyme fructose bisphosphatase is highly regulated, being much higher when glucose levels are high (Funayama et al. 1980). Impairing the degradation of this enzyme, how- ever, is usually of little biological consequence because the activity of the protein is rapidly inhibited by regulatory phosphorylation after a shift in carbon source (Mazon et al. 1982). Although protein degradation may prevent the inadvertent reactivation of this critical regulatory factor, it is clearly of secondary importance.

We show here that rapid degradation of $\alpha 2$ is in fact a crucial component of the yeast mating-type switching mechanism. Most significantly, the persistence of $\alpha 2$ after an $\alpha$-to-a genetic switch impairs phenotypic switching by two distinct means. First, $\alpha 2$ homodimers continue to repress a-cell-specific genes that need to be activated for a mating behavior. Second, the long-lived $\alpha 2$ protein associates with newly synthesized MATa-encoded al protein, and $\mathbf{a} 1-\alpha 2$ heterodimers repress genes required for mating. Therefore, Ub-dependent proteolysis constitutes a critical component of this developmental switch by preventing ectopic repression of either of the two transcriptional programs that are under $\alpha 2$ control. Many transcription factors in other eukaryotes also participate in multiple, functionally distinct complexes, and therefore the different mechanisms by which ubiquitin-dependent proteolysis reprograms transcription during yeast differentiation are likely to be used in these organisms as well.

\section{Results}

Phenotypic switching is impaired when $\alpha 2$ is stabilized

To determine the biological function of $\alpha 2$ protein degradation, we made use of trans-acting mutations that remove components of the ubiquitination machinery that target $\alpha 2$ for Ub-dependent proteolysis. The half-life of $\alpha 2$ is only modestly increased in cells singly deficient for the E2 enzymes Ubc4 or Ubc6. However, the stability of $\alpha 2$ is greatly enhanced in $u b c 4 \Delta u b c 6 \Delta$ cells, in which both factors are deleted (Fig. 1A). This reflects the existence of two distinct ubiquitination pathways that promote $\alpha 2$ proteolysis (Chen et al. 1993). The Ubc6 pathway uses an E3 Ub-protein ligase called Doa10 (Swanson et al. 2001). Simultaneously disrupting both ubiquitination pathways with a $u b c 4 \Delta$ doa10 $\Delta$ double mutation also stabilized the entire steady-state pool of $\alpha 2$ (Fig. 1B). Based on chromatin immunoprecipitation (ChIP) assays, the $\alpha 2$ protein persisted on one of its target genes in

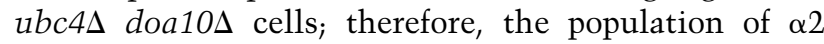
bound to its DNA operators was also strongly stabilized when both ubiquitination pathways were deleted (Fig. 1C).

We initially analyzed the mating behavior of mutants defective in $\alpha 2$ degradation using a macroscopic, colonybased assay to determine if $\alpha 2$ metabolic instability is necessary for cells to change their phenotype following a DNA switch at the MAT locus. During the growth of a single haploid spore into a colony, homothallic (switching-competent) strains have the ability to regain the diploid state (Fig. 2A; Oshima and Takano 1971). After germination, homothallic haploid spores divide to produce 
A

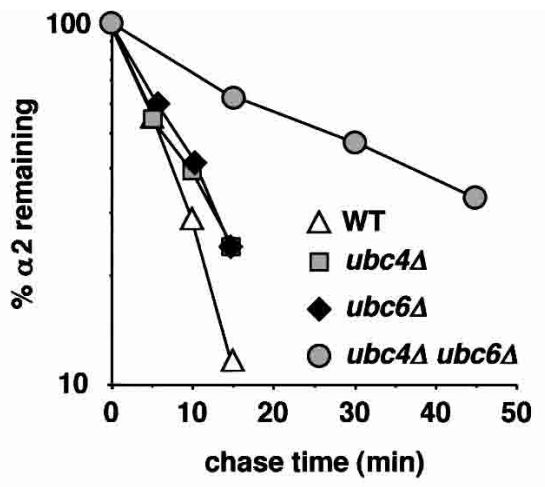

B $\begin{array}{ll}\text { WT } & \text { ubc4 } \\ \text { doa } 10\end{array}$
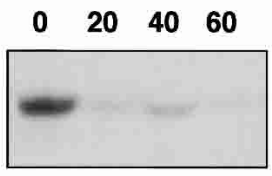

020

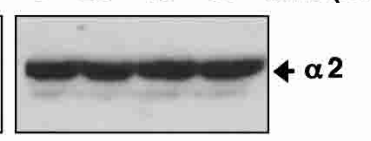

C ChIP Input 0204060
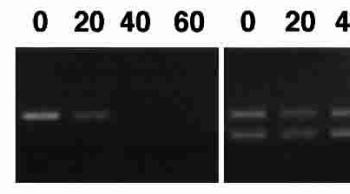

4060
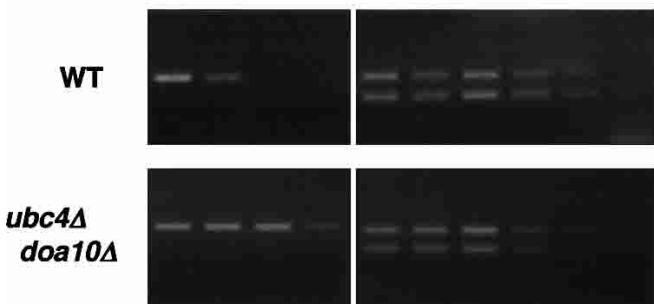

4 STE6 4 Control

Figure 1. The metabolic stability of $\alpha 2$ is governed primarily by two distinct ubiquitination pathways. $(A)$ The in vivo degradation of $\alpha 2$ assayed by pulse-chase analysis. The haploid $u b c$ mutant strains used in these assays were heterothallic derivatives of the homothallic strains used in the switching experiments described below. Quantitation of $\alpha 2$ proteolysis showed that the half-life of $\alpha 2$ increased less than twofold in the singly mutant $u b c$ strains and approximately sixfold in the $u b c 4 \Delta$ $u b c 6 \Delta$ double mutant. $(B)$ The stability of the steady-state pool of $\alpha 2$ is also increased in cells lacking both of the ubiquitination pathways that promote $\alpha 2$ proteolysis. $\alpha 2$ stability was assayed in wild-type and $u b c 4 \Delta$ doa $10 \Delta$ strains by blocking further protein synthesis with cycloheximide and measuring $\alpha 2$ protein levels at subsequent time points by anti- $\alpha 2$ immunoprecipitation/immunoblotting. $(C)$ The $u b c / d o a$ mutations stabilize the DNA-bound fraction of $\alpha 2$. Binding of $\alpha 2$ to STE6, an a-specific gene, was analyzed in wild-type and $u b c 4 \Delta$ doa $10 \Delta$ strains by chromatin immunoprecipitation (ChIP) and PCR at the indicated time points after inhibiting protein synthesis with cycloheximide. DOA3 was used as a nonspecific control. DNA purified from each input extract and threefold dilutions of the 60min input extract (triangle) were analyzed in parallel. The data in $B$ and $C$ are from different aliquots of the same cultures.

a population of cells, some of which have switched mating type (Hicks and Herskowitz 1976). Neighboring cells with opposite mating types readily mate to form diploids, which then grow to produce a colony of nonmating diploid cells. Efficient diploidization of isolated homothallic haploid cells is generally regarded as the raison d'être of the mating-type switching mechanism: The a/ $\alpha$ diploid state is more resistant to environmental insults such as ionizing radiation, and diploid cells can differentiate meiotically into highly resilient spores.

As expected for homothallic strains, colonies derived from single wild-type spores are largely composed of nonmating diploid cells. When tested qualitatively for mating competence, these cells did not mate efficiently with haploid mating-type tester strains. This was revealed by the lack of growth on selective medium, where mating with the testers is required for cell viability (Fig. $2 \mathrm{~B}$, top). In contrast, colonies derived from $u b c 4 \Delta u b c 6 \Delta$ spores retained the ability to mate with both tester strains and therefore contained many mating-competent haploid cells of both mating types (Fig. 2B, bottom). Pre-

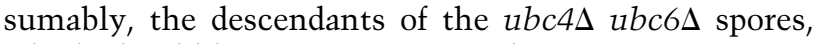
which should be competent to undergo MAT gene conversion (see below), included many cells that could not efficiently switch their sexual phenotype and did not mate with their neighbors to form diploids. The resulting colony therefore bears a large number of haploid cells. Thus, the efficient diploidization process of homothallic cells, which requires a rapid switch in mating phenotype, is impaired in cells in which the transcriptional repressor $\alpha 2$ is stabilized.

To characterize this phenotypic switching defect at the cellular level, we analyzed the ability of single cells to switch from the $\alpha$ to a mating type by a quantitative microscopic $\alpha$-factor pheromone confrontation assay (Strathern and Herskowitz 1979). Cells of the a matingtype respond to $\alpha$-factor by arresting their growth and adopting a characteristic morphology, whereas $\alpha$ cells are unaffected by the pheromone and continue to divide. Mating-type switching from $\alpha$ to $\mathbf{a}$ is determined by a change in the ability of a cell to respond to $\alpha$-factor. When $u b c$ mutant cells were assayed in this manner, a strong correlation was observed between the frequency with which cells changed mating phenotype and the metabolic stability of the $\alpha 2$ protein in these cells. Singly mutant $u b c 4 \Delta$ or $u b c 6 \Delta$ strains, which exhibit only slightly elevated $\alpha 2$ half-lives (Fig. 1A; Chen et al. 1993), switched their mating phenotype and responded to pheromone with efficiencies similar to that of wild-type cells $(-70 \%-85 \%$; Fig. 2 C). In striking contrast, few cells that lack both Ubc enzymes (ubc4s ubc6s strains) switched mating phenotype ( $6 \%$; Fig. $2 C)$. In these double mutants, $\alpha 2$ degradation is strongly inhibited (Fig. 1; Chen et al. 1993).

The interpretation of these experiments with transacting mutations may be compromised by the fact that the Ubc enzymes act on several different substrates. However, $\alpha 2$ degradation is unusual in that either of two different ubiquitination pathways is sufficient for maintaining relatively rapid proteolysis of the protein (Fig. 1; Chen et al. 1993). In contrast, the degradation of many substrates of the Ub-proteasome pathway strongly depends on the expression of a single specific $U B C$ gene (Dohmen et al. 1991; Schwob et al. 1994; Johnson et al. 1995; Drury et al. 1997; Hampton and Bhakta 1997; Henchoz et al. 1997). Because a phenotypic switching defect 
Figure 2. Trans-acting mutations that stabilize $\alpha 2$ block phenotypic switching. (A) Mating-type switching promotes diploidization in homothallic strains. (B) A rapid switch in mating phenotype is required for efficient diploidization. Homothallic spores of the indicated genotype were dissected and allowed to grow into colonies. The mating phenotype of cells in the colony was determined by a qualitative mating test with the indicated mating-type tester strains. The ability to mate (that is, the presence of haploid cells in the colony) was scored as cell growth on minimal medium. $(C)$ Simultaneous disruption of both pathways that promote $\alpha 2$ ubiquitination and degradation inhibits cells from switching their phenotype. The mating phenotype of individual cells of the indicated genotype was determined by their response to $\alpha$ factor, that is, whether or not they arrest their growth and change their cell morphology. The numbers denote the number of cells that have switched/total number of cells assayed. (D) Disruption of an E3 Ubprotein ligase that promotes the degradation of $\alpha 2$ inhibits phenotypic switching, as determined by confrontation with $\alpha$ pheromone.
A

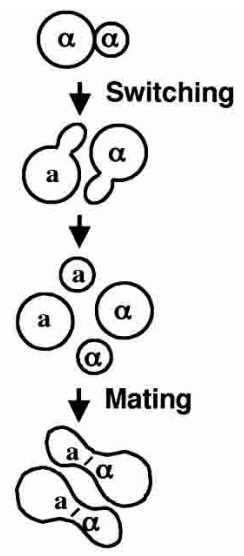

Non-mating Diploid

B
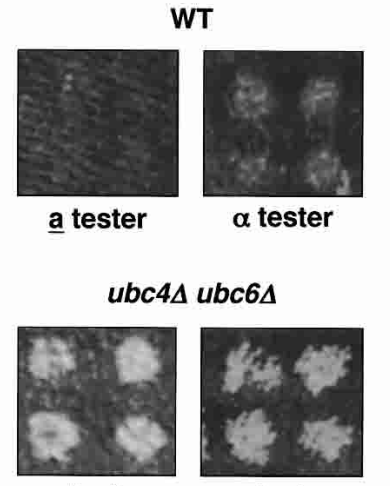

a tester

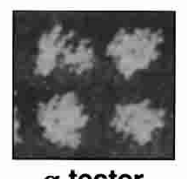

$\alpha$ tester

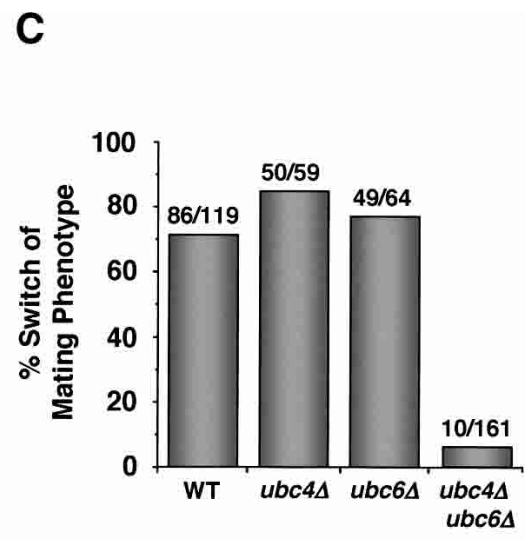

D

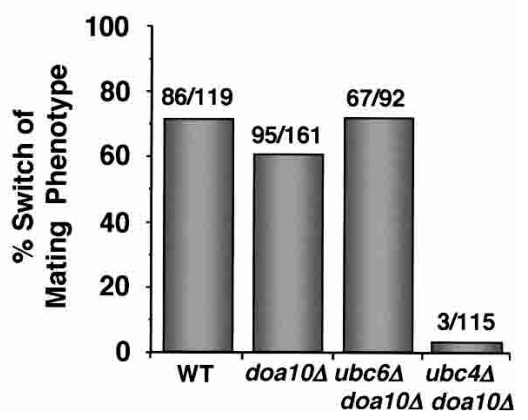

was observed only in the ubc4s ubc6s double-mutant strain in which both $\alpha 2$ ubiquitination pathways were blocked, this suggests that this mutant phenotype is likely caused by the stabilization of $\alpha 2$ and not by some other factor.

To strengthen this inference, we analyzed the effects of eliminating the E3 Ub-protein ligase Doa10 rather than one of the E2/Ubcs. Doa10 acts on an even more limited set of substrates than do the E2s. The results of these experiments paralleled those presented in Figure 2C. Like the $u b c 4 \Delta$ or $u b c 6 \Delta$ single mutants, singly mutant doa10s cells underwent mating-type switching with wild-type frequency (Fig. 2D). Consistent with the fact that Doa10 functions solely in the Ubc6/Ubc7 pathway of $\alpha 2$ degradation (Swanson et al. 2001), ubc6s doa10 $\Delta$ double-mutant cells could switch from the $\alpha$ to the a phenotype with efficiencies similar to those of wild type as well. However, combining deletion mutations of UBC4 with DOA10 yielded $\alpha$ cells that only rarely switched their mating phenotype (Fig. 2D). Thus, cells that lack the ubiquitination machinery that specifically targets $\alpha 2$ for rapid degradation cannot efficiently switch their mating phenotype.

\section{Stabilization of $\alpha 2$ inhibits $\alpha$-to-a transdifferentiation}

A series of complementary experiments was undertaken to strengthen the argument that it is $\alpha 2$ stabilization that is specifically responsible for the dramatic defects in $\alpha$-to-a cell-type switching seen in the aforementioned mutants. We first asked whether these mutations might stabilize repressors of the switching process itself. Ash1 and Mpt5 are key negative regulators of HO-catalyzed gene conversion at MAT (Bobola et al. 1996; Sil and Herskowitz 1996; Tadauchi et al. 2001). Eliminating these factors in the $u b c 4 \Delta u b c 6 \Delta$ background, however, had no effect on the observed switching defects (data not shown).

Another way to address whether the phenotypic switching defect was caused by $\alpha 2$ stabilization, rather than by stabilization of some negative regulator of gene conversion at $M A T$, would be to examine whether the ubc/doa mutant cells were exclusively impaired in switching from $\alpha$ to a and not the reverse. In fact, we observed that the failure to switch mating phenotypes was highly asymmetric. As shown in Figure $3 \mathrm{~A}$, the same $u b c 4 \Delta u b c 6 \Delta$ and $u b c 4 \Delta$ doa $10 \Delta$ double mutants that failed to switch efficiently from $\alpha$ to a as measured by pheromone response, were completely normal when the opposite a-to- $\alpha$ switch was assayed. As a control for evaluating whether our microscopic assay for phenotypic switching could detect a defect in a-to- $\alpha$ interconversion, the behavior of swi5 mutants was examined. SWI5 is necessary for the expression of the HO endonuclease that initiates the switching process (Stern et al. 1984). As expected, we failed to detect either a-to- $\alpha$ or 


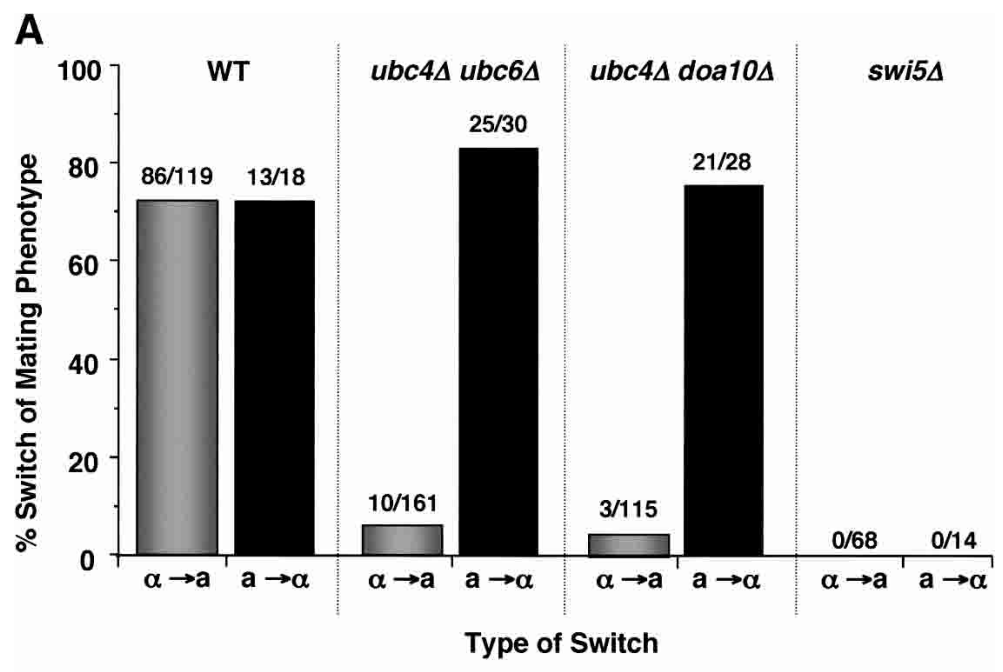

B

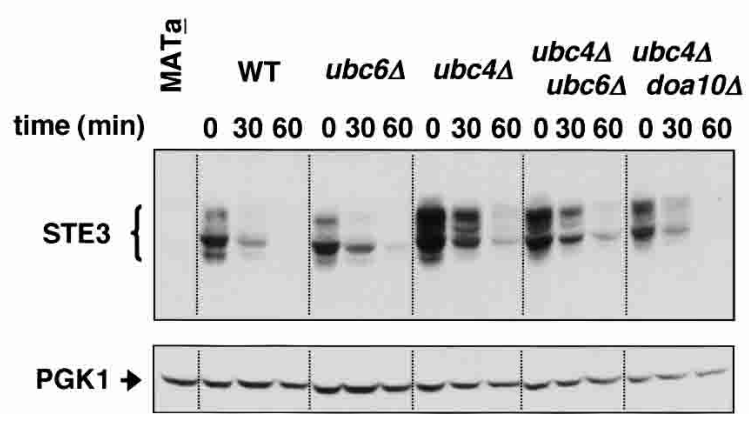

$\alpha$-to-a mating-type interconversions in a swi5s strain (Fig. 3A). From these results, we conclude that the persistence or misregulation of an $\alpha$-cell-specific gene product-such as $\alpha 2$-is the cause of the switching defects observed in the $u b c 4 \Delta u b c 6 \Delta$ and $u b c 4 \Delta$ doa $10 \Delta$ strains.

A candidate $\alpha$-specific gene product whose persistence could impair the $\alpha$-to-a phenotypic switch is Ste3, because the inappropriate expression of Ste3 in MATa strains results in cells that do not respond to mating pheromone (Hirsch and Cross 1993). This inhibition requires the protein Asg7 inasmuch as the pheromone response is restored in MATa asg7D strains that ectopically express Ste3 (Kim et al. 2000; Roth et al. 2000). If a failure to degrade the normally short-lived Ste3 protein in nascent a $u b c 4 \Delta u b c 6 \Delta$ and a $u b c 4 \Delta$ doa $10 \Delta$ mitotic segregants was responsible for the block to adopting the a phenotype, then removing Asg7 would allow bypass of the block. However, deleting the ASG7 gene had no effect on the mating-type switching defect of the $u b c / d o a$ mutants (Table 1), suggesting that the stabilization of Ste3 is not the cause of this phenotype. Direct assays of Ste3 degradation in the double-mutant strains supported this conclusion (Fig. 3B). Although Ste3 degradation was weakly impaired in singly mutant $u b c 4 \Delta$ cells, as observed previously (Roth and Davis 1996), the stability of Ste3 did not increase further in $u b c 4 \Delta u b c 6 \Delta$ or $u b c 4 \Delta$ doa10s cells.

The transcription of almost all $\alpha$-cell-specific genes depends on the transcriptional activator $\alpha 1$; the only ex-
Figure 3. Phenotypic switching is defective only in the $\alpha$-to-a direction. (A) Phenotypic switching of cells of the indicated genotypes was assayed in both $\alpha$-to-a and a-to- $\alpha$ directions. For comparison, the $\alpha$-to-a switching data from Figure 2 are presented. (B) Ste3 stability is not significantly altered in the mutants that stabilize $\alpha 2$. Ste3 stability was assayed by blocking further protein synthesis with cycloheximide and measuring protein levels at subsequent time points by anti-Ste3 immunoblot analysis. To control for loading, the blot was stripped and reprobed with an anti-Pgk1 antibody. ceptions are the MAT $\alpha$ genes themselves, MAT $\alpha 2$ and $M A T \alpha 1$ (Strathern et al. 1981). To determine if the persistence or misregulation of $\alpha 1$ or an $\alpha 1$-dependent gene product(s) was responsible for the phenotypic switching defect of the $u b c 4 \Delta u b c 6 \Delta$ and $u b c 4 \Delta$ doa $10 \Delta$ strains, we deleted the $M A T \alpha 1$ gene in these backgrounds and then tested for suppression of the defect using the $\alpha$-factor confrontation assay. As can be seen in Table 1, loss of $\alpha 1$ did not alter the phenotypic switching defects of the mutant strains. Importantly, mutation of $\alpha 1$ by itself does not affect the switching process (Table 1; Strathern and Herskowitz 1979). Note that $\alpha 2$ could not be examined

Table 1. Deletion of ASG7 or $\alpha 1$ does not suppress the phenotypic switching defects of Ub-conjugation mutants

\begin{tabular}{|c|c|}
\hline Strain & Switching frequency ${ }^{\mathrm{a}}(\%)$ \\
\hline Wild type & 72 (86 of 119$)$ \\
\hline $\operatorname{asg} 7 \Delta$ & $78(93$ of 119$)$ \\
\hline$\alpha 1 \Delta$ & $60(53$ of 88$)$ \\
\hline$u b c 4 \Delta u b c 6 \Delta$ & $6(10$ of 161$)$ \\
\hline$u b c 4 \Delta$ ubc6s asg $7 \Delta$ & $3(1$ of 39$)$ \\
\hline$u b c 4 \Delta u b c 6 \Delta \alpha 1 \Delta$ & $7(5$ of 70$)$ \\
\hline$u b c 4 \Delta$ doa10s & $3(3$ of 115$)$ \\
\hline ubc4s doa10s asg7s & $3(2$ of 62$)$ \\
\hline$u b c 4 \Delta$ doa $10 \Delta \alpha 1 \Delta$ & $5(5$ of 93$)$ \\
\hline
\end{tabular}

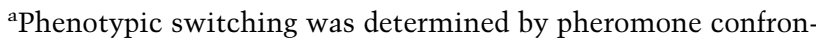
tation as in Figure 2C. 
in this way because it is required both for sporulation, a necessary step in generating the homothallic spores used in the assay, and for preventing $\alpha$-factor receptor expression in wild-type $\alpha$ cells, a prerequisite for the pheromone confrontation assay used to examine switching.

These multiple lines of evidence demonstrate that $u b c 4 \Delta u b c 6 \Delta$ and $u b c 4 \Delta$ doa $10 \Delta$ mutants are specifically impaired in the $\alpha$-to-a phenotypic switch, and this block does not require any $\alpha$-specific genes other than, by default, the $\alpha 2$ protein. Together with the identical E2 and E3 dependencies for both efficient phenotypic switching and $\alpha 2$ degradation, the data strongly imply that stabilization of $\alpha 2$ is the cause of the differentiation defect in these mutant strains.

\section{Overexpression of $\alpha 2$ impairs phenotypic switching}

By blocking the degradation of $\alpha 2$, the $u b c / d o a$ mutations should lead to an increase in the amount of $\alpha 2$ protein that persists in cells that have switched from $M A T \alpha$ to MATa. If this increase in $\alpha 2$ levels contributed to the phenotypic switching defect of the mutants, one would predict that augmenting $\alpha 2$ levels by other means should mimic, at least partially, the reduced frequency of $\alpha$-to-a differentiation. An alternative and independent means of raising protein levels would be either to increase the synthesis rate of $\alpha 2$ or to generate point mutations in $\alpha 2$ that specifically impair its degradation without altering its repressor functions. Alleles of $\alpha 2$ with the desired properties have not been isolated, and it would be difficult to rule out quantitative changes in repression capacity as contributing factors to any observed switching defects of these $\alpha 2$ mutants. Furthermore, unexpected effects on the proteolysis of $\alpha 2$ by mutations in a well-characterized degradation signal have been observed, including aberrant degradation products and targeting to proteolytic pathways distinct from those that act on the wild-type protein (Johnson et al. 1998). Because of this, we decided to overproduce the wild-type $\alpha 2$ protein by replacing the native $\alpha 2$ promoter with two different promoters containing binding sites for the strong transcriptional activators tetR-VP16 or Gal4. Cell-type switching was analyzed by $\alpha$-factor confrontation in single cells carrying these promoter swaps. Wildtype cells expressing either activator but lacking the promoter substitution still efficiently changed their mating phenotype (Fig. 4). On the other hand, cells overexpressing $\alpha 2$ from either of the two promoters had a diminished capacity to differentiate to the a phenotype. This decrease was not due simply to the insertion of heterologous promoter and marker gene sequences into the $M A T$ locus because switching occurred at wild-type levels in cells bearing the $\mathrm{P}_{\text {teto }}$ promoter substitution but lacking strong expression of the cognate trans-activator (data not shown).

These results suggest that cells expressing high levels of $\alpha 2$ have difficulty clearing the excess $\alpha 2$ protein quickly enough for the a-cell-specific genetic program to be initiated. The $\alpha 2$ protein will still be degraded rapidly under these conditions (Hochstrasser and Varshavsky

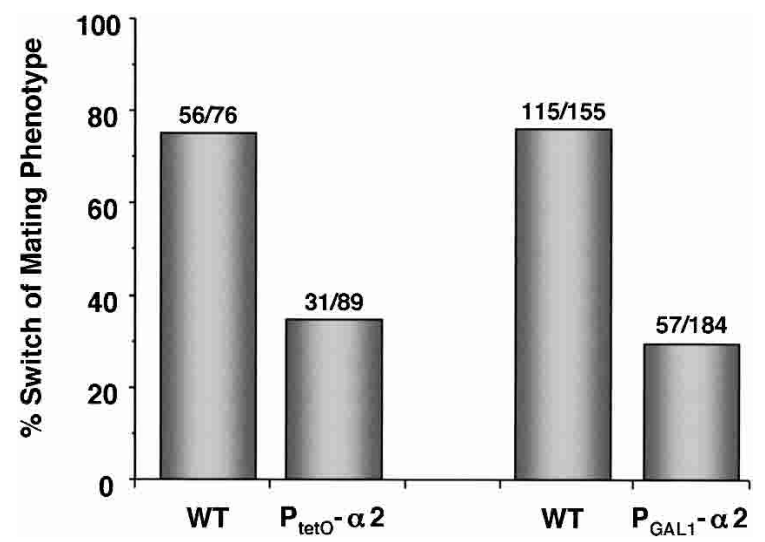

Figure 4. Raising the steady-state level of $\alpha 2$ by overexpression inhibits phenotypic switching. The $\alpha 2$ promoter was replaced with a CYC1 minimal promoter containing tetO operator sites or with the GAL1 promoter. Strains carrying the tet $\mathrm{O}_{7}$ promoter swap also expressed the tetR-VP16 activator and were assayed for switching in the absence of tetracycline. Wild-type cells lacked the tet $\mathrm{O}_{7}$ substitution, but expressed the tetR-VP16 activator. Cells with the GAL1 promoter replacement or a wildtype strain without a promoter substitution were assayed on galactose media.

1990), which probably accounts for the higher residual level of phenotypic switching in the $\alpha 2$ overexpression strains compared with the $u b c / d o a$ mutants. The observation that these two different mechanisms for altering $\alpha 2$ protein levels have the same qualitative phenotypic consequences strongly supports the idea that rapid elimination of $\alpha 2$ is required for cells to switch their mating phenotype. This conclusion was confirmed by experiments showing complete suppression of the $\alpha$-to-a phenotypic switching defects by a combination of bypassing the repression of a direct gene target of $\alpha 2$ and eliminating the ability of perdurable $\alpha 2$ to bind a 1 after a genetic switch at the MAT locus (see below).

\section{Normal genetic switching in ubc/doa mutants}

The near absence of $\alpha$-to-a mating-type switching in the $u b c / d o a$ mutants could be caused by an epigenetic block to changing differentiation states, as suggested above, or it could conceivably arise from an underlying defect in the $\alpha$-to-a DNA interconversion at the MAT locus. To determine whether cells that lack the ubiquitination machinery needed to degrade $\alpha 2$ rapidly can nevertheless undergo MAT gene conversion, we directly monitored the DNA recombination process during mating-type switching. Although the $\mathrm{HO}$ endonuclease that initiates switching is normally produced in a fraction of cells during a small window of the cell cycle, a transient ectopic induction of $\mathrm{HO}$ expression can be used to initiate gene switching nearly simultaneously in all cells of a population. This allows for the physical analysis of DNA extracted at various times after $\mathrm{HO}$ induction (Holmes and Haber 1999).

Strains carrying $\mathrm{HO}$ under the control of a galactose- 
inducible promoter undergo a mating-type gene conversion event after incubation in galactose. Using this system, MAT DNA cleavage and allele interconversion were analyzed over a time course by Southern hybridization (Fig. 5A). These experiments showed that the DNA double-strand break produced by the $\mathrm{HO}$ endonuclease was repaired with the same kinetics regardless of whether the $U B C / D O A$ genes were deleted or not (Fig. $5 \mathrm{~B})$. Thus, the gene conversion mechanism of matingtype switching was intact and functioned with wild-type efficiency in cells in which the $\alpha 2$ protein was stabilized.

Although these experiments allowed quantitative measurements of the recombination kinetics at MAT af-

A
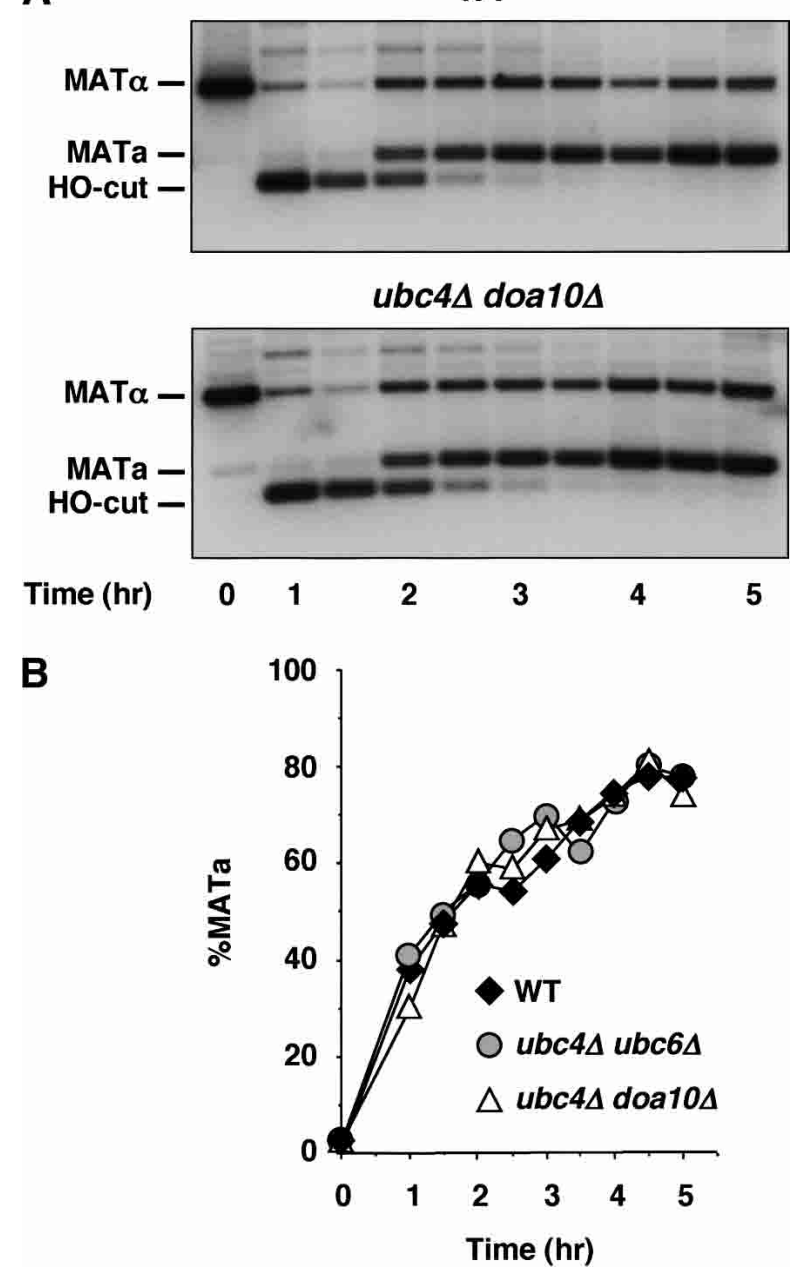

Figure 5. The gene conversion process that underlies $M A T$ switching occurs normally in cells that cannot rapidly degrade

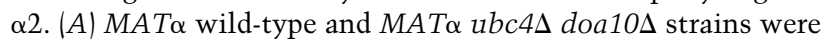
induced to switch to MATa by a 1-h induction of $P_{G A L}-H O$. Genomic DNA isolated during a time course was digested and analyzed by Southern hybridization analysis using a $M A T$-specific probe. Similar results were obtained with a $u b c 4 \Delta u b c 6 \Delta$ strain (data not shown). (B) The hybridization signals from the Southern blots were quantitated, and the percentage of MATa signal relative to the sum of the MATa and MAT $\alpha$ signals at each time point is plotted versus time. ter HO cleavage was initiated, they did not rule out the possibility that $\mathrm{HO}$ is not induced properly in the $\mathrm{ubc} /$ doa mutants. The asymmetry of mating-type switching defects in these mutants suggested that $\mathrm{HO}$ was induced and that DNA switching proceeded normally because these cells could readily change from the a to the $\alpha$ phenotype (Fig. 3A). To test this more directly-and in cells switching from the $\alpha$ to the a genotype-we developed a single-cell visual assay that followed $M A T$ genetic switching directly, rather than relying on the functional properties of the allele expressed at the MAT locus (Fig. 6A). In this way, genetic switching is analyzed in the same homothallic cells as those used for the phenotypic switching experiments. The visual assay used a yeast strain in which the coding sequence for green fluorescent protein (GFP) replaced the mating-type information at the silent donor site HMR $\boldsymbol{a}(h m r:: G F P)$. Genes located at $H M R$ are maintained in a silent state by the assembly of a repressive chromatin structure; instead of being actively expressed, this locus serves as a donor of genetic information during mating-type gene switching (Haber 1998). Although two different silent loci exist, $H M R$ is preferentially used during MAT $\alpha$ to MATa switching (Strathern and Herskowitz 1979; Klar et al. 1982). Thus, $M A T \alpha$ cells with an hmr::GFP replacement will not express GFP initially, and only after the GFP expression cassette is copied into the MAT locus will the cells exhibit GFP fluorescence.

To determine if the $u b c / d o a$ mutant strains were capable of genetic switching, we analyzed hmr::GFP derivatives for their ability to switch from a nonfluorescent to a fluorescent state. Figure $6 \mathrm{~B}$ shows that wild-type mother cells, which have the capacity to switch (Hicks and Herskowitz 1976), produced progeny that expressed GFP. The descendants of daughter cells did not undergo a genetic mating-type switch and, as expected, remained nonfluorescent. Importantly, wild-type cells and ubc/ doa mutant strains switched on GFP fluorescence with similar frequency, even though the $u b c / d o a$ mutants did not change their mating phenotype (Fig. 6B,C). These results demonstrate that cells lacking the ubiquitination enzymes that promote $\alpha 2$ proteolysis nonetheless switch their mating-type information at the DNA level. Furthermore, these findings suggest that rapid degradation of $\alpha 2$ is necessary for the tight coupling of a phenotypic switch to a genetic change at the mating-type locus.

\section{Mechanism of the phenotypic switching defect}

Persistence of the $\alpha 2$ protein in $u b c / d o a$ mutant strains after a genetic switch might lead to the improper regulation of several cell-type-specific gene expression programs controlled by $\alpha 2$. First, the long-lived $\alpha 2$ protein could interact with newly synthesized a1. The resulting a1- $\alpha 2$ heterodimers, which are normally found only in a $\alpha$ diploid cells, would repress expression of genes specific to haploid cells (and necessary for mating). Second, the mating phenotype of a newly switched cell could be altered by the continued repression of a-cell-specific genes by $\alpha 2$. To determine which of these mechanisms is 
A

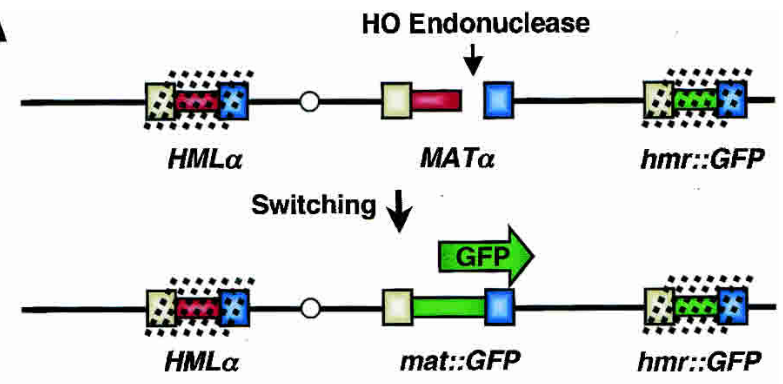

B
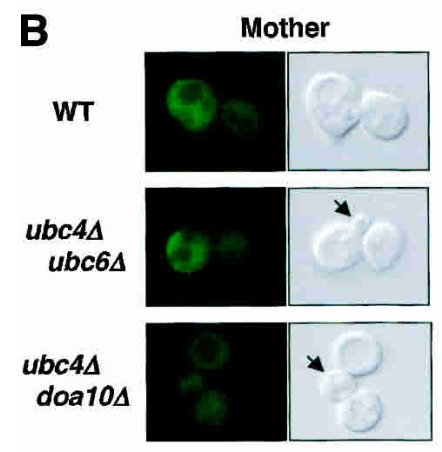

C

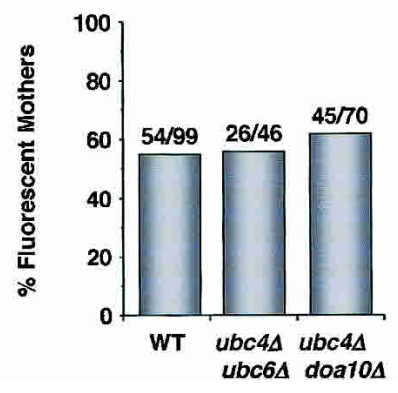

Figure 6. A single-cell visual assay shows that cells inhibited in phenotypic switching undergo a genetic switching event. $(A)$ Experimental design. GFP, under the control of the URA3 promoter, was integrated at the silent (dotted lines) donor locus $H M R$. Upon induction of $H O$ in mother cells, $H M R$ is used as the preferred donor of genetic information in MAT $\alpha$ cells. This results in the transposition of the GFP coding sequence into the active MAT locus. (B) Fluorescence and DIC images of mother and daughter cell progeny of the indicated genotypes grown in the presence of $\alpha$-factor. Wild-type mother cell descendants express GFP, whereas daughter-cell progeny, which do not switch mating-type, are nonfluorescent. The descendants of ubc4s $u b c 6 \Delta$ and $u b c 4 \Delta$ doa $10 \Delta$ mother cells undergo a genetic switch to express GFP, but fail to switch phenotypically, as indicated by their budding in the presence of $\alpha$-factor (arrows). The homothallic strains used in these experiments are derivatives of the strains utilized in Figure 2. $(C)$ Similar frequencies of genetic switching were observed for all genotypes. The numbers indicate the number of fluorescent mother cell progeny/total number of cells assayed.

responsible for the phenotypic switching defects of the $u b c / d o a$ mutant strains, we sought to restore the normal response to $\alpha$ mating pheromone by manipulating either the haploid-cell- or the a-cell-specific gene expression program.
The hmr::GFP replacement strains described above no longer contain functional $\boldsymbol{a} 1$ coding information at the silent $H M R$ locus and therefore cannot express the a1 protein after genetic switching of MAT. Nevertheless, the $u b c / d o a$ mutant strains carrying this $h m r$ modification are still strongly impaired in phenotypic switching, although a partial recovery was observed (Fig. 7). Therefore, repression of haploid-specific genes by the formation of an ectopic a $1-\alpha 2$ heterodimer in the $u b c / d o a$ mutant cells is not by itself sufficient to account for the strong defect in their switching behavior. Furthermore, this observation indicates that the physical interaction of $\alpha 2$ and a1, which also stabilizes $\alpha 2$ (Johnson et al. 1998), is not required for the switching phenotype of ubc/doa strains.

Of the a-cell-specific genes, persistent repression of $S T E 2$, which encodes the $\alpha$-factor receptor, could lead to a defect in switching when measured by the $\alpha$-factor confrontation assay. To examine if the failure to derepress STE2 is responsible for the ubc/doa switching phenotype, we constructed strains that express STE2 from a galactose-inducible promoter. However, when assayed on galactose media to drive expression of STE2 independently of $\alpha 2$, the $u b c /$ doa $P_{G A L}-S T E 2$ cells were still defective in changing their mating phenotype, although here too a partial rescue was seen (Fig. 7). Apparently, the ectopic expression of STE2 alone is also not sufficient to reverse the phenotypic switching defects of ubc/doa strains.

In striking contrast to their effects when examined

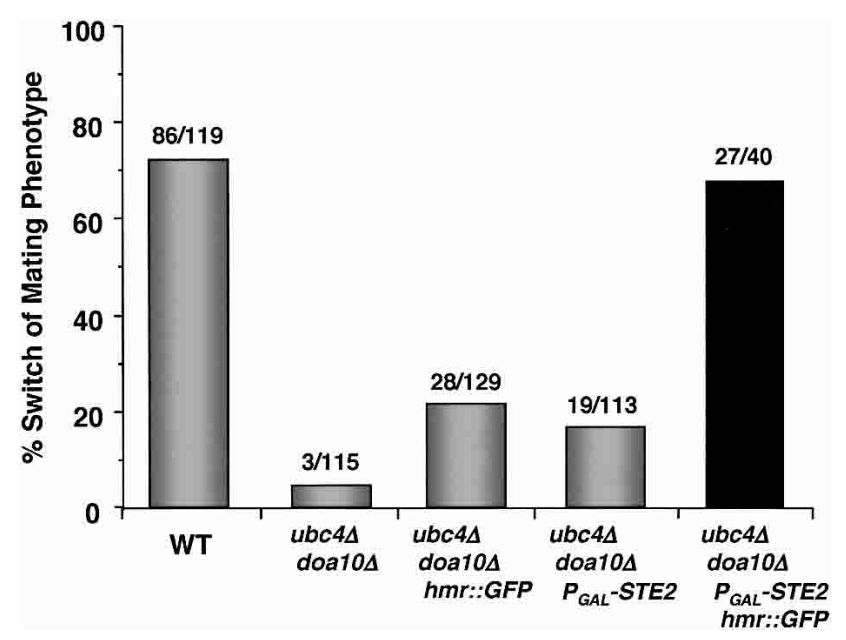

Figure 7. The phenotypic switching defect of $u b c / d o a$ mutants is fully reversed by the simultaneous removal of al information from $H M R$ and the ectopic expression of the a-specific gene STE2. Phenotypic switching was determined by pheromone confrontation, as in Figure 2. For comparison, the data for wildtype and $u b c 4 \Delta$ doa10 $\Delta$ cells from Figure $2 \mathrm{D}$ are presented.

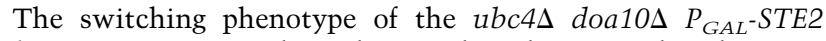
$h m r:: G F P$ strains is dependent on the galactose-induced expression of STE2, because only $\sim 24 \%$ (11 of 45 ) of these cells phenotypically switch when assayed on raffinose media. Similar results were obtained with $u b c 4 \Delta u b c 6 \Delta$ strains carrying the $P_{G A L^{-}}$STE2 and $h m r:: G F P$ alleles (data not shown). 
alone, combining the hmr::GFP and $P_{G A L}$-STE2 alleles in the same cell resulted in complete suppression of the mating-type switching deficiencies of $u b c / d o a$ mutant strains (Fig. 7). Therefore, cells expressing a long-lived $\alpha 2$ protein can switch to the a-cell state after an $\alpha$-to-a gene conversion only if both the $\alpha$-factor receptor gene is removed from $\alpha 2$-mediated repression and a1, a binding partner of $\alpha 2$ in diploid cells, is eliminated. Inappropriate repression of either haploid-specific genes by a1- $\alpha 2$ or the a-specific gene STE2 by $\alpha 2$ is sufficient to lead to a strong defect in phenotypic switching in the ubc/doa mutants. Furthermore, because both STE2 and the haploid-specific genes are direct targets of $\alpha 2$, these suppression results provide compelling evidence that the differentiation defect of the $u b c / d o a$ strains is caused by the persistence of the $\alpha 2$ protein.

\section{Discussion}

The data presented here demonstrate that the correct switch in cellular phenotype that occurs during the development of a cell lineage requires not only induction of new transcriptional programs but also proteolytic dismantling of a pre-existing regulatory network. We have shown that the Ub-proteasome pathway must remove an important determinant of yeast cellular identity before a cell can differentiate and change its phenotypic state. Metabolic stabilization of the $\alpha 2$ transcription factor, a master regulator expressed in MAT $\alpha$ cells, strongly inhibits the phenotypic switching of cell type without altering the genotypic switching event that occurs at the mating-type locus. Importantly, our experiments indicate that the persistence of the $\alpha 2$ protein after a cell has genetically changed from MAT $\alpha$ to MATa disrupts the acquisition of the new a mating phenotype by two distinct molecular mechanisms. To our knowledge, this represents the first example in eukaryotic cell differentiation in which both the requirement for destroying a specific transcriptional regulator has been established and the specific molecular processes that demand such degradation have been determined.

The need for yeast cells to be able to switch back and forth between different mating phenotypes places a strong developmental constraint on the metabolic stability of a master regulatory factor like $\alpha 2$. By the same argument, the other mating-type transcription factors, $\alpha 1$ and $\mathbf{a} 1$, should also be unstable proteins, as has been found (see above). If either of these transcription factors persists after cell-type switching, the mating behavior of the progeny cells should be disrupted in a manner analogous to that observed here when $\alpha 2$ was stabilized.

It is interesting that $\alpha 2$ proteolysis contributes to two distinct regulatory mechanisms important for resetting the gene expression program after a MAT $\alpha$-to-MATa switch (Fig. 7). Failure to degrade $\alpha 2$ rapidly blocks the derepression of STE2, an a-cell-specific gene (asg). This implies either that the Ub pathway is required for removal of the $\alpha 2$ repressor from asg DNA operator sites or that an exchangeable but long-lived $\alpha 2$ pool can rebind the operators (along with the corepressor proteins
Mcm1, Tup1, and Ssn6) with sufficient kinetics to prevent a transcriptionally active state from forming. Assembly of long-lived $\alpha 2$ into active heterodimers with newly synthesized a1 in the ubc/doa mutants can also be inferred from the data in Figure 7. Hence, to form a1- $\alpha 2$ heterodimers, the MATa1 and MAT $\alpha 2$ genes need not be cotranscribed, as normally occurs in a/ $\alpha$ diploid cells, and the population of $\alpha 2$ molecules is therefore not sequestered on chromatin sites or in homodimer complexes. Both of these Ub-dependent proteolytic mechanisms, the elimination of active transcriptional regulatory complexes and the prevention of inappropriate assembly of new regulatory complexes, are likely to underlie cell-type interconversions in other cell lineages.

Coupling regulated changes in the synthesis of a transcription factor with its constitutive degradation, as occurs in yeast cell-type switching, is one means by which developmental transitions in other organisms might occur. For instance, developmental timing in Caenorhabditis elegans is probably regulated in this manner. The products of the heterochronic genes lin-14 and lin-41 are expressed at different times in development to coordinate the temporal pattern of cell division and differentiation in a wide variety of tissues. Normal development requires the synthesis of LIN-14 and LIN-41 to be downregulated at specific larval stages, and once this occurs, these regulatory proteins are cleared from cells (Ruvkun and Giusto 1989; Slack et al. 2000). An alternative mechanism for the proteolytic control of cell lineage specification is one in which the degradation of cell-type regulators is triggered in some fashion by signals linked to the developmental transition itself, which may or may not be accompanied by regulated changes in synthesis of the regulators.

Although it is premature to speculate on the relative prevalence of the two aforementioned mechanisms of coupling protein degradation to cell differentiation, it is very likely that Ub-mediated proteolysis will often contribute by degrading determinants of a previous developmental stage. This might be particularly common in transdifferentiation, wherein a "terminally" differentiated cell type can convert to another. For instance, fully differentiated pancreatic cells can sometimes transdifferentiate into hepatocytes. Pancreatic cells can be induced to undergo transdifferentiation into liver cells through the ectopic expression of the liver-enriched transcription factor C/EBP $\beta$ (Shen et al. 2000). This switch in differentiation state not only requires that liver-specific genes be induced but also that the gene expression program that specifies the pancreas be dismantled. Given the similarities to the events described here and the pervasiveness of Ub-dependent protein degradation, one can anticipate that the Ub-mediated proteolysis of the key pancreas-specifying transcription factor PTF-1 is involved. Conversely, switches in the opposite direction (Horb et al. 2003), which have also been observed in human liver cancer (Wolf et al. 1990), might reflect the inappropriate degradation of C/EBP $\beta$.

As in the example of yeast cell-type determination, normal developmental transitions may also use Ub-de- 
pendent mechanisms to degrade regulators that determine a previous cellular state. During lymphocyte differentiation, for instance, the transcription factors PU.1 and Pax5 are important for early lymphoid development, and their subsequent down-regulation appears to be necessary for the formation of the T-cell lineage and the differentiation of plasma cells, respectively (Rothenberg and Anderson 2002; Schebesta et al. 2002). Ub-mediated degradation of regulators such as PU.1 and Pax5 may push cells down a specific developmental pathway by ridding them of the regulators that defined the prior stage of differentiation.

In summary, we have found that the Ub-dependent degradation of a transcription factor that determines cell type in yeast provides an important epigenetic mechanism for mediating changes in developmental state. The known Ub-dependent degradation of many other transcription factors in both yeast and more complex eukaryotes suggests that this regulatory mechanism will be of broad developmental significance.

\section{Materials and methods}

\section{Plasmids}

The $H O$ disruption plasmid pho $\Delta::$ URA3 was made by substituting a HindIII fragment containing URA3 for the $H O$ sequences in pHO (Nasmyth 1985). The plasmid pRS306-P $\mathrm{CUP}_{\text {C }} /$ HA-tTA was constructed in two steps. First, a PCR fragment containing tTA (tetR-VP16) was subcloned into YATAG200 (GenBank accession no. U37457), an expression vector containing the CUP1 promoter, CYC1 terminator, and a 5' HA tag. The $\mathrm{BamHI} / \mathrm{ClaI}$ fragment from this resulting plasmid was then subcloned into pRS306. To construct pCM225- $\Delta$ tTA, the tetRVP16 coding sequences and CMV promoter in pCM225 (Johnston et al. 2002; Petracek and Longtine 2002) were removed by XhoI/EcoRI digestion and religation. To construct an integrating $\mathrm{P}_{\mathrm{GAL}}$-STE2 plasmid, the EcoRI/BamHI fragment from LHp203 (kindly provided by L. Hicke, Northwestern University) was subcloned into pRS306. The plasmid pHMR :: $\mathrm{P}_{\mathrm{URA}^{-}}$ GFP/URA3 was made in a series of steps. A promoter fragment from URA3 was amplified from genomic DNA with BamHI and $\mathrm{PacI}$ ends. This $\mathrm{BamHI} / \mathrm{PacI}$ fragment was subcloned into similarly digested pSVA12 (Mateus and Avery 2000). The BamHI/ BgIII fragment containing $\mathrm{P}_{\mathrm{URA} 3}$-GFP was then subcloned into BgIII-digested pHMRa1-invert/URA3. This plasmid is a derivative of pHMRa (which contains the HindIII/EcoRI fragment encompassing $H M R \boldsymbol{a}$ in pUC19) and was constructed by creating a second BgIII site in the coding sequence of $H M R \boldsymbol{a} 1$ by PCR and inverting the $\sim 450$-bp $B g l I I$ fragment by BgIII digestion and religation. A fragment containing URA3 was then inserted into the NruI site flanking $H M R$.

\section{Yeast strains}

The homothallic yeast strains used here are derivatives of XW117, which was obtained from Jim Haber (Brandeis University). Heterothallic derivatives of these strains were constructed by disrupting $H O$ with the $B a m H I / E c o R I$ fragment of phos::URA3. The ho ade $3:: G A L-H O$ strains described here are derived from XW702, which was also obtained from Jim Haber. Specific gene deletions, integrations, and substitutions were made using standard methods of transforming linearized plas- mid fragments or PCR products (Johnston et al. 2002; Petracek and Longtine 2002). Proper integrations and substitutions were confirmed by PCR and segregation analysis.

Homothallic strains carrying the tet $\mathrm{O}_{7}$ promoter replacement were made by first integrating $\mathrm{pRS} 306 / \mathrm{P}_{\mathrm{CUP}}-\mathrm{HA}$-tTA into the URA3 locus. An anti-HA immunoreactive, $\mathrm{URA}^{+}$integrant was made homozygous by sporulation and tetrad dissection. The resulting strain was then transformed with a PCR fragment containing the tet $\mathrm{O}_{7}$ promoter and kanMX marker, using pCM225$\Delta \mathrm{tTA}$ as a template and primers containing flanking sequences homologous to $\alpha 2$. Strains carrying the GAL1 promoter replacement were made by transforming a PCR fragment generated using pFA6a-kanMX6-PGAL1 (Johnston et al. 2002; Petracek and Longtine 2002) as a template. These latter strains switch out the promoter substitution when grown on glucose-containing media, presumably because of glucose repression of $\alpha 2$ and subsequent derepression of $H O$. Strains were therefore propagated on YPGal. However, because galactose-induced overexpression of $\alpha 2$ blocks sporulation of these strains, a GAL4-estrogen receptor-VP16 fusion protein expression construct (Louvion et al. 1993) was integrated into these strains. This construct allowed the expression level of GAL1 promoter to be titrated by $\beta$-estradiol. Conditions were found in which sporulation occurs and the GAL1 promoter substitution is retained. Because PCR analysis shows that only $\sim 70 \%$ of spores keep the promoter modification after sporulation under these conditions, the data presented overestimate the frequency of switching in the $P_{G A L 1}-\alpha 2$ strains.

Strains with the hmr::GFP modification were constructed by transforming the EcoRI/XhoI fragment from pHMR:: $\mathrm{P}_{\mathrm{URA}^{-}}$ GFP/URA3. Integration at $H M R$ was verified by PCR analysis, and the modification was made homozygous by sporulation and tetrad dissection. The $u b c 4 \Delta u b c 6 \Delta$ and $u b c 4 \Delta$ doa $10 \Delta$ strains were transformed with a TRP1 UBC4 plasmid before sporulation to ensure efficient switching and diploidization. Strains that lose this plasmid were then selected on plates containing 5 -fluoroanthranilic acid.

The $P_{G A L}-S T E 2$ construct was integrated at the URA3 locus after digesting pRS306/ $/ \mathrm{P}_{\mathrm{GAL}}-\mathrm{STE} 2$ with $\mathrm{NcoI}$. Integrations were verified by anti-Ste2 Western blotting. Strains containing both $P_{G A L^{-}}$STE2 and $h m r:: G F P$ alleles were generated by crossing spores carrying the single integrations.

\section{Mating-type switching assays}

Pedigree analysis was performed as described (Hicks and Herskowitz 1976; Strathern and Herskowitz 1979), except that $\alpha$-factor (U.S. Biological) was dissolved at a concentration of $5 \mu \mathrm{g} / \mathrm{mL}$ in $4 \%$ YPD plates. The $P_{G A L 1}-\alpha 2$ strains were dissected on plates containing $3 \%$ raffinose $/ 3 \%$ galactose as the carbon source. Strains containing the $P_{t e t O^{-}} \alpha 2$ substitution were dissected on plates supplemented with $100 \mu \mathrm{M} \mathrm{CuSO}_{4}$ to induce expression of the tetR-VP16 activator. To ensure that the $M A T \alpha$ spores carrying $P_{G A L}-S T E 2$ did not arrest when confronted with $\alpha$-factor, spores were germinated on I-plates containing $\alpha$-factor/ $3 \%$ raffinose and then transferred across the septum to inducing media containing $\alpha$-factor $/ 3 \%$ raffinose $/ 3 \%$ galactose after cells had divided once and rebudded. This allows for genetic switching and entry into the next division cycle before expression of STE2 is induced.

To visualize switching of the homothallic hmr::GFP strains, sporulated cultures were dissected on plates of complete synthetic media supplemented with $4 \%$ glucose, $5 \mathrm{mM}$ adenine, and $5 \mu \mathrm{g} / \mathrm{mL} \alpha$-factor. A microscope slide was embedded in the dissection plates, prepared by pouring molten media into plates containing a slide so that a very thin slab of agar covers the 
slide. After germination of the spores, mother and daughter cells were separated by micromanipulation. The slides were then cut out of the agar plate and examined by DIC and fluorescence microscopy.

Mating-type switching induced by the galactose-dependent expression of $H O$ was performed essentially as described (Holmes and Haber 1999). Southern blots of StyI-digested genomic DNA were hybridized with a ${ }^{32} \mathrm{P}$-labeled probe prepared by random priming of the $\sim 500-b p$ StyI/NdeI fragment adjacent to the MAT locus. The hybridization signals were quantitated on a PhosphorImager.

\section{Protein degradation assays}

Pulse-chase experiments measuring the stability of $\alpha 2$ were performed as described (Chen et al. 1993). Degradation rates were determined after quantitation on a PhosphorImager. The haploid $u b c$ mutant strains used in pulse-chase assays were heterothallic derivatives of the homothallic strains used in the switching experiments.

Cycloheximide-chase experiments to follow Ste3 degradation were performed by growing strains to $\mathrm{OD}_{600} \sim 1$ in synthetic complete media followed by concentrating the cells to $10 \mathrm{OD} /$ $\mathrm{mL}$ in synthetic media containing $0.5 \mathrm{mg} / \mathrm{mL}$ cycloheximide. Aliquots (2.5 $\mathrm{OD}_{600}$ equivalents) were removed at the indicated time points, and protein extracts were prepared by boiling for 10 min in protein gel loading buffer. Immunoblots were probed with affinity-purified anti-Ste3 antibodies provided by Nick Davis (Wayne State University, Detroit, MI). Immunoblots were stripped and reprobed with an anti-Pgk1 monoclonal antibody (Molecular Probes) to control for loading. Proteins were detected by ECL (Amersham Biosciences). To follow $\alpha 2$ degradation after the initiation of mating-type switching (Fig. 1B,C), XW702 wild-type and congenic ubc4s doa10s strains were grown to $\mathrm{OD}_{600} \sim 1$ in YP-lactate and $H O$ expression was induced for $1 \mathrm{~h}$ by adding galactose to $2 \%$ final concentration. Cycloheximide was added to a final concentration of $0.2 \mathrm{mg} /$ $\mathrm{mL}$, and aliquots $\left(25\right.$ and $50 \mathrm{OD}_{600}$ equivalents for immunoprecipitation/immunoblotting and ChIP, respectively) were removed at the indicated time points. Protein extracts were immunoprecipitated with $\alpha-\alpha 2$ antibodies and visualized by immunoblotting.

\section{ChIP assays}

Chromatin was prepared and immunoprecipitations were performed as described previously (Aparicio et al. 1997), except that cross-linking was performed with $2 \%$ formaldehyde (final concentration) for $5 \mathrm{~min}$ in the presence of $20 \mathrm{mM}$ sodium azide and the DNA was purified with QIAquick spin columns (QIAGEN). Polyclonal $\alpha-\alpha 2$ antibodies were used for immunoprecipitation. The sequences of PCR primers used to amplify promoter regions of STE6 (-390/-29, spanning the $\alpha 2$ operator) and DOA3 $(-381 /-113)$ are available on request. Control experiments (data not shown) demonstrate that the immunoprecipitated signal is antibody- and cross-linking-dependent and specific to MAT $\alpha$ cells.

\section{Acknowledgments}

We dedicate this work to the memory of Ira Herskowitz. We thank Jim Haber for strains and plasmids, Linda Hicke for plasmids and the anti-Ste2 antibody, and Nick Davis for the antiSte3 antibody. We are grateful to T. Serio, J. Coleman, D. Schwartz, and R. Swanson for critiques of the manuscript. This work was supported by a grant from the National Institutes of Health (GM46904 to M.H.) and by funds from the Rhode Island
Foundation. J.D.L. was supported initially by a fellowship (PF4397) from the American Cancer Society.

The publication costs of this article were defrayed in part by payment of page charges. This article must therefore be hereby marked "advertisement" in accordance with 18 USC section 1734 solely to indicate this fact.

\section{References}

Akiyama, H., Chaboissier, M.-C., Martin, J.F., Schedl, A., and de Crombrugghe, B. 2002. The transcription factor Sox9 has essential roles in successive steps of the chondrocyte differentiation pathway and is required for expression of Sox 5 and Sox6. Genes \& Dev. 16: 2813-2828.

Aparicio, O.M., Weinstein, D.M., and Bell, S.P. 1997. Components and dynamics of DNA replication complexes in $S$. cerevisiae: Redistribution of MCM proteins and Cdc45p during S phase. Cell 91: 59-69.

Black, B.L. and Olson, E.N. 1998. Transcriptional control of muscle development by myocyte enhancer factor-2 (MEF2) proteins. Annu. Rev. Cell Dev. Biol. 14: 167-196.

Bobola, N., Jansen, R.P., Shin, T.H., and Nasmyth, K. 1996. Asymmetric accumulation of Ashlp in postanaphase nuclei depends on a myosin and restricts yeast mating-type switching to mother cells. Cell 84: 699-709.

Chen, P. and Hochstrasser, M. 1995. Biogenesis, structure, and function of the yeast 20S proteasome. EMBO $J$. 14: 2620-2630.

Chen, P., Johnson, P., Sommer, T., Jentsch, S., and Hochstrasser, M. 1993. Multiple ubiquitin-conjugating enzymes participate in the in vivo degradation of the yeast MAT $\alpha 2$ repressor. Cell 74: 357-369.

Dohmen, R.J., Madura, K., Bartel, B., and Varshavsky, A. 1991. The $\mathrm{N}$-end rule is mediated by the UBC2(RAD6) ubiquitinconjugating enzyme. Proc. Natl. Acad. Sci. 88: 7351-7355.

Drury, L.S., Perkins, G., and Diffley, J.F. 1997. The Cdc4/34/53 pathway targets Cdc6p for proteolysis in budding yeast. EMBO J. 16: 5966-5976.

Edgar, B.A., Weir, M.P., Schubiger, G., and Kornberg, T. 1986. Repression and turnover pattern fushi tarazu RNA in the early Drosophila embryo. Cell 47: 747-754.

Funayama, S., Gancedo, J.M., and Gancedo, C. 1980. Turnover of yeast fructose-bisphosphatase in different metabolic conditions. Eur. J. Biochem. 109: 61-66.

Glimcher, L.H. and Singh, H. 1999. Transcription factors in lymphocyte development-T and B cells get together. Cell 96: $13-23$.

Haber, J.E. 1998. Mating-type gene switching in Saccharomyces cerevisiae. Annu. Rev. Genet. 32: 561-599.

Hampton, R.Y. and Bhakta, H. 1997. Ubiquitin-mediated regulation of 3-hydroxy-3-methylglutaryl-CoA reductase. Proc. Natl. Acad. Sci. 94: 12944-12948.

Henchoz, S., Chi, Y., Catarin, B., Herskowitz, I., Deshaies, R.J., and Peter, M. 1997. Phosphorylation- and ubiquitin-dependent degradation of the cyclin-dependent kinase inhibitor Farlp in budding yeast. Genes \& Dev. 11: 3046-3060.

Hershko, A. and Ciechanover, A. 1998. The ubiquitin system. Annu. Rev. Biochem. 67: 425-479.

Herskowitz, I. 1985. Master regulatory loci in yeast and $\lambda$. Cold Spring Harbor Symp. Quant. Biol. 50: 565-574.

Hicks, J.B. and Herskowitz, I. 1976. Interconversion of yeast mating types. I. Direct observations of the action of the homothallism (HO) gene. Genetics 83: 245-258.

Hirsch, J.P. and Cross, F.R. 1993. The pheromone receptors inhibit the pheromone response pathway in Saccharomyces cerevisiae by a process that is independent of their associated $\mathrm{G} \alpha$ protein. Genetics 135: 943-953. 
Hochstrasser, M. 1995. Ubiquitin, proteasomes, and the regulation of intracellular protein degradation. Curr. Opin. Cell Biol. 7: 215-223.

Hochstrasser, M. and Varshavsky, A. 1990. In vivo degradation of a transcriptional regulator: The yeast $\alpha 2$ repressor. Cell 61: 697-708.

Hochstrasser, M., Ellison, M.J., Chau, V., and Varshavsky, A. 1991. The short-lived MAT $\alpha 2$ transcriptional regulator is ubiquitinated in vivo. Proc. Natl. Acad. Sci. 88: 46064610.

Holmes, A. and Haber, J.E. 1999. Physical monitoring of HOinduced homologous recombination. Methods Mol. Biol. 113: 403-415.

Horb, M.E., Shen, C.N., Tosh, D., and Slack, J.M. 2003. Experimental conversion of liver to pancreas. Curr. Biol. 13: 105115.

Hoyt, M.A., Knight, D.M., Das, A., Miller, H.I., and Echols, H. 1982. Control of phage $\lambda$ development by stability and synthesis of cII protein: Role of the viral cIII and host hflA, himA and himD genes. Cell 31: 565-573.

Johnson, E.S., Ma, P.C.M., Ota, I.M., and Varshavsky, A. 1995. A proteolytic pathway that recognizes ubiquitin as a degradation signal. J. Biol. Chem. 270: 17442-17456.

Johnson, P.R. 1997. "Regulated turnover of the Saccharomyces cerevisiae MAT transcription factors." Ph.D. Thesis, The University of Chicago, Chicago, IL.

Johnson, P.R., Swanson, R., Rakhilina, L., and Hochstrasser, M. 1998. Degradation signal masking by heterodimerization of MAT $\alpha 2$ and MATa1 blocks their mutual destruction by the ubiquitin-proteasome pathway. Cell 94: 217-227.

Johnston, M., Riles, L., and Hegemann, J.H. 2002. Gene disruption. Methods Enzymol. 350: 290-315.

Kellerman, K.A., Mattson, D.M., and Duncan, I. 1990. Mutations affecting the stability of the fushi tarazu protein of Drosophila. Genes \& Dev. 4: 1936-1950.

Kim, J., Bortz, E., Zhong, H., Leeuw, T., Leberer, E., Vershon, A.K., and Hirsch, J.P. 2000. Localization and signaling of $G_{\beta}$ subunit Ste4p are controlled by a-factor receptor and the a-specific protein Asg7p. Mol. Cell. Biol. 20: 8826-8835.

Klar, A.J., Hicks, J.B., and Strathern, J.N. 1982. Directionality of yeast mating-type interconversion. Cell 28: 551-561.

Lange, R. and Hengge-Aronis, R. 1994. The cellular concentration of the $\sigma \mathrm{S}$ subunit of RNA polymerase in Escherichia coli is controlled at the levels of transcription, translation, and protein stability. Genes \& Dev. 8: 1600-1612.

Li, S., Li, Y., Carthew, R.W., and Lai, Z.C. 1997. Photoreceptor cell differentiation requires regulated proteolysis of the transcriptional repressor Tramtrack. Cell 90: 469-478.

Louvion, J.-F., Havaux-Copf, B., and Picard, D. 1993. Fusion of GAL4-VP16 to a steroid-binding domain provides a tool for gratuitous induction of galactose-responsive genes in yeast. Gene 131: 129-134.

Mateus, C. and Avery, S.V. 2000. Destabilized green fluorescent protein for monitoring dynamic changes in yeast gene expression with flow cytometry. Yeast 16: 1313-1323.

Mazon, M.J., Gancedo, J.M., and Gancedo, C. 1982. Inactivation of yeast fructose-1,6-bisphosphatase. In vivo phosphorylation of the enzyme. I. Biol. Chem. 257: 1128-1130.

Nakashima, K., Zhou, X., Kunkel, G., Zhang, Z., Deng, J.M., Behringer, R.R., and de Crombrugghe, B. 2002. The novel zinc finger-containing transcription factor osterix is required for osteoblast differentiation and bone formation. Cell 108: $17-29$.

Nasmyth, K. 1985. At least 1400 base pairs of 5 '-flanking DNA is required for the correct expression of the $\mathrm{HO}$ gene in yeast. Cell 42: 213-223.
Nasmyth, K. and Shore, D. 1987. Transcriptional regulation in the yeast life cycle. Science 237: 1162-1170.

Oshima, Y. and Takano, I. 1971. Mating types in Saccharomyces: Their convertibility and homothallism. Genetics 67: 327-335

Pan, Q., Garsin, D.A., and Losick, R. 2001. Self-reinforcing activation of a cell-specific transcription factor by proteolysis of an anti- $\sigma$ factor in B. subtilis. Mol. Cell 8: 873-883.

Petracek, M.E. and Longtine, M.S. 2002. PCR-based engineering of yeast genome. Methods Enzymol. 350: 445-469.

Rosen, E.D. and Spiegelman, B.M. 2000. Molecular regulation of adipogenesis. Annu. Rev. Cell Dev. Biol. 16: 145-171.

Roth, A.F. and Davis, N.G. 1996. Ubiquitination of the yeast a-factor receptor. J. Cell Biol. 134: 661-674.

Roth, A.F., Nelson, B., Boone, C., and Davis, N.G. 2000. Asg7pSte3p inhibition of pheromone signaling: Regulation of the zygotic transition to vegetative growth. Mol. Cell. Biol. 20: $8815-8825$.

Rothenberg, E.V. and Anderson, M.K. 2002. Elements of transcription factor network design for T-lineage specification. Dev. Biol. 246: 29-44.

Ruvkun, G. and Giusto, J. 1989. The Caenorhabditis elegans heterochronic gene lin-14 encodes a nuclear protein that forms a temporal developmental switch. Nature 338: 313-319.

Schebesta, M., Heavey, B., and Busslinger, M. 2002. Transcriptional control of B-cell development. Curr. Opin. Immunol. 14: 216-223.

Schwob, E., Böhm, T., Mendenhall, M.D., and Nasmyth, K. 1994. The B-type cyclin kinase inhibitor $\mathrm{p} 40^{\mathrm{SIC} 1}$ controls the G1 to $S$ transition in S. cerevisiae. Cell 79: 233-244.

Shen, C.N., Slack, J.M., and Tosh, D. 2000. Molecular basis of transdifferentiation of pancreas to liver. Nat. Cell Biol. 2: $879-887$.

Sil, A. and Herskowitz, I. 1996. Identification of asymmetrically localized determinant, Ash1p, required for lineage-specific transcription of the yeast HO gene. Cell 84: 711-722.

Slack, F.J., Basson, M., Liu, Z., Ambros, V., Horvitz, H.R., and Ruvkun, G. 2000. The lin-41 RBCC gene acts in the C. elegans heterochronic pathway between the let-7 regulatory RNA and the LIN-29 transcription factor. Mol. Cell 5: 659669

Stern, M., Jensen, R., and Herskowitz, I. 1984. Five SWI genes are required for expression of the $\mathrm{HO}$ gene in yeast. J. Mol. Biol. 178: 853-868.

Strathern, J.N. and Herskowitz, I. 1979. Asymmetry and directionality in production of new cell types during clonal growth: The switching pattern of homothallic yeast. Cell 17: 371-381.

Strathern, J., Hicks, J., and Herskowitz, I. 1981. Control of cell type in yeast by the mating type locus. The $\alpha 1-\alpha 2$ hypothesis. J. Mol. Biol. 147: 357-372.

Swanson, R., Locher, M., and Hochstrasser, M. 2001. A conserved ubiquitin ligase of the nuclear envelope/endoplasmic reticulum that functions in both ER-associated and Mat $\alpha 2$ repressor degradation. Genes \& Dev. 15: 2660-2674.

Tadauchi, T., Matsumoto, K., Herskowitz, I., and Irie, K. 2001. Post-transcriptional regulation through the HO 3'-UTR by Mpt5, a yeast homolog of Pumilio and FBF. EMBO J. 20: $552-$ 561.

Tang, A.H., Neufeld, T.P., Kwan, E., and Rubin, G.M. 1997. PHYL acts to down-regulate TTK88, a transcriptional repressor of neuronal cell fates, by a SINA-dependent mechanism. Cell 90: 459-467.

Wolf, H.K., Burchette, J.L., Garcia, J.A., and Michalopoulos, G. 1990. Exocrine pancreatic tissue in human liver: A metaplastic process? Am. J. Surg. Pathol. 14: 590-595. 


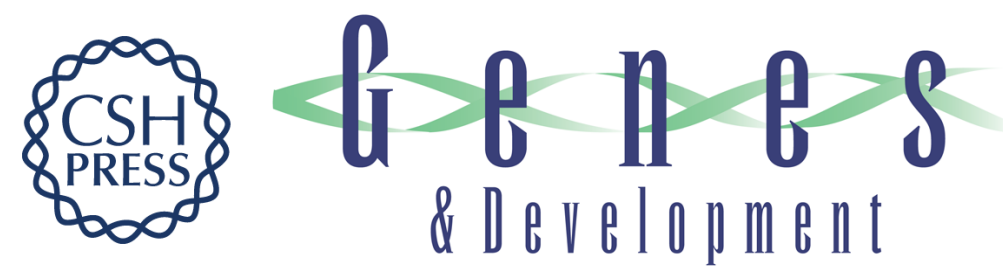

\section{Ubiquitin-dependent degradation of the yeast Mat $\alpha 2$ repressor enables a switch in developmental state}

Jeffrey D. Laney and Mark Hochstrasser

Genes Dev. 2003, 17:

Access the most recent version at doi:10.1101/gad.1115703

References This article cites 58 articles, 20 of which can be accessed free at: http://genesdev.cshlp.org/content/17/18/2259.full.html\#ref-list-1

License

Email Alerting

Receive free email alerts when new articles cite this article - sign up in the box at the top Service right corner of the article or click here.

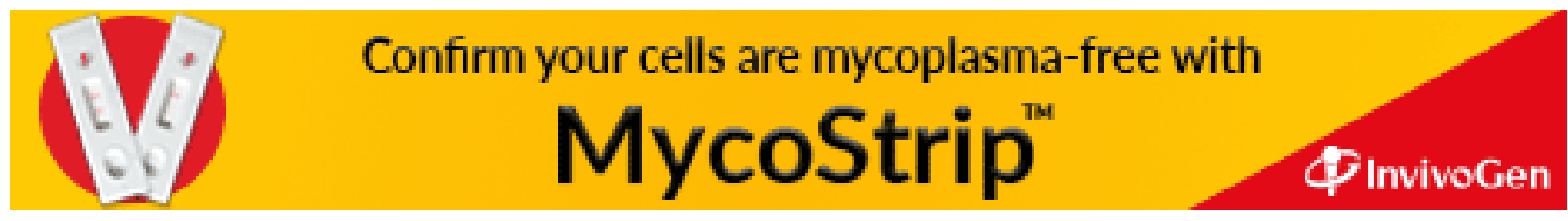

